\title{
SEISMIC PERFORMANCE AND STRENGTHENING OF TRADITIONAL MASONRY BUILDINGS IN THE CITY CENTRE OF COIMBRA
}

\author{
Vicente, R. ${ }^{1}$, Rodrigues, ${ }^{1}{ }^{1}$ and Varum, $\mathbf{H} .{ }^{1}$ \\ ${ }^{1}$ Civil Engineering Department, University of Aveiro \\ Campus Universitário de Santiago, 3810-193 Aveiro, Portugal \\ romvic@civil.ua.pt, hrodrigues@aveiro-norte.ua.pt, hvarum@civil.ua.pt
}

Keywords: Old city centres, existing masonry, finite element modelling, structural evaluation, damage, seismic vulnerability, dynamic behaviour, strengthening techniques.

\begin{abstract}
The increasing concern and consequent appraisal on durability, conservation state and changeable use and function of old buildings in urban centres relies a great deal on the structural safety evaluation of vertical load capacity but also the capable resistance to horizontal forces. The need to assess seismic vulnerability, particularly of the traditional masonry buildings is a key issue. Particular attention has been put upon the building stock of the old city centre of Coimbra, mainly constituted by old masonry load-bearing buildings of significant architectural value.

The evaluation of the seismic vulnerability of old buildings is essential in the definition of the strengthening needs and minimization of possible damages due to seismic actions, in safeguarding of built heritage or in the identification of critical buildings. This paper intends to contribute for the assessment of old buildings considering the local seismic risk.

A three dimensional model was developed for an aggregate of four buildings. The finite element modelling of these buildings has intended to identify structural fragilities, help understand the damages detected in the existing structures (crack opening) and evaluate the global structural safety of this type of buildings.

It will be presented the main results obtained in this study, interpreted the structural damage, stress distribution and verified the global stability and its consequences. The dynamic response of such constructions to seismic actions has allowed studying the structural vulnerability. Different strengthening techniques to improve the global behaviour of these buildings were modelled and analysed. Efficiency comparison of the strengthening strategies is also discussed.
\end{abstract}




\section{INTRODUCTION}

Old load-bearing masonry buildings exist all around the world, with special significance in urban historical city centres, representing the majority of the building stock. These buildings, besides their patrimonial, cultural and architectural heritage value, frequently present a high level of degradation, urging for the need of conservation and strengthening actions.

Recently, the consciousness of the public opinion begun to evidence to this need through the creation of safeguarding and preservation policies for the architectural valued buildings and urban aggregates. The inoperativeness of the responsible agents and the lack of strategies and policies in the last half of the XX century in this domain drove the built urban stock to a situation of deep degradation in a great number of historical centres [1]. Worsening this context, it is witnessed the adoption of intrusive and inadequate rehabilitation and conservation practices, using new materials and construction techniques (concrete) on structural and non-structural elements, moving away the knowledge of traditional practices, the capability and connection of the solutions with the existent, leading to the discharacterization of the urban and patrimonial image.

A great percentage of the built urban stock of the historical city centre of Coimbra is constituted by buildings dated of XVIII to the mid XX century (after the 1755 Lisbon earthquake), most of them built without any earthquake resistant criteria (no specific construction rules). Even the later constructions do not follow the seismic resisting system "gaiola pombalina", developed after the Lisbon earthquake, neither appropriate construction rules nor techniques.

In prone areas of seismic action (Central and Southern Portugal), the need to take preventive measures of structural strengthening to minimise the damages, or avoid losses of incalculable value is surely a priority. Such measures require a previous evaluation of the expected seismic response through modelling representative buildings of this type of construction.

The concern on structural safety under seismic actions has lead to the assessment of seismic vulnerability that should be a priority in the mitigation of the seismic risk and the planning and development of strengthening intervention strategy, with appropriate technical decision and financial support.

The case studied in this paper is an aggregate of four buildings that typically represent the constructive typology and constitution of the old masonry buildings in Coimbra. This paper provides information on the constructive and structural details of the old buildings in the old city centre of Coimbra and discusses the seismic and dynamic behaviour, identifying structural fragilities and consequently their vulnerability. It also analyses the efficiency of three commonly adopted strengthening schemes.

\section{BUILDING DESCRIPTION AND STRUCTURAL TYPOLOGY}

The aggregate of buildings studied is included in the irregular urban mesh of the old city centre of Coimbra (see figure 1). In this area of the city, a renewal and rehabilitation process is taking its first steps as a collaborative framework between the local authorities (city council) and the University of Coimbra [2].

The buildings studied belong to the oldest area of the historical city centre, featuring architectural aspects (one direction staircase, stone framing and window glazing characteristics) which evidence that these buildings belongs to the period between the XVIII and XIX century (see figures 2 and 3 ). 


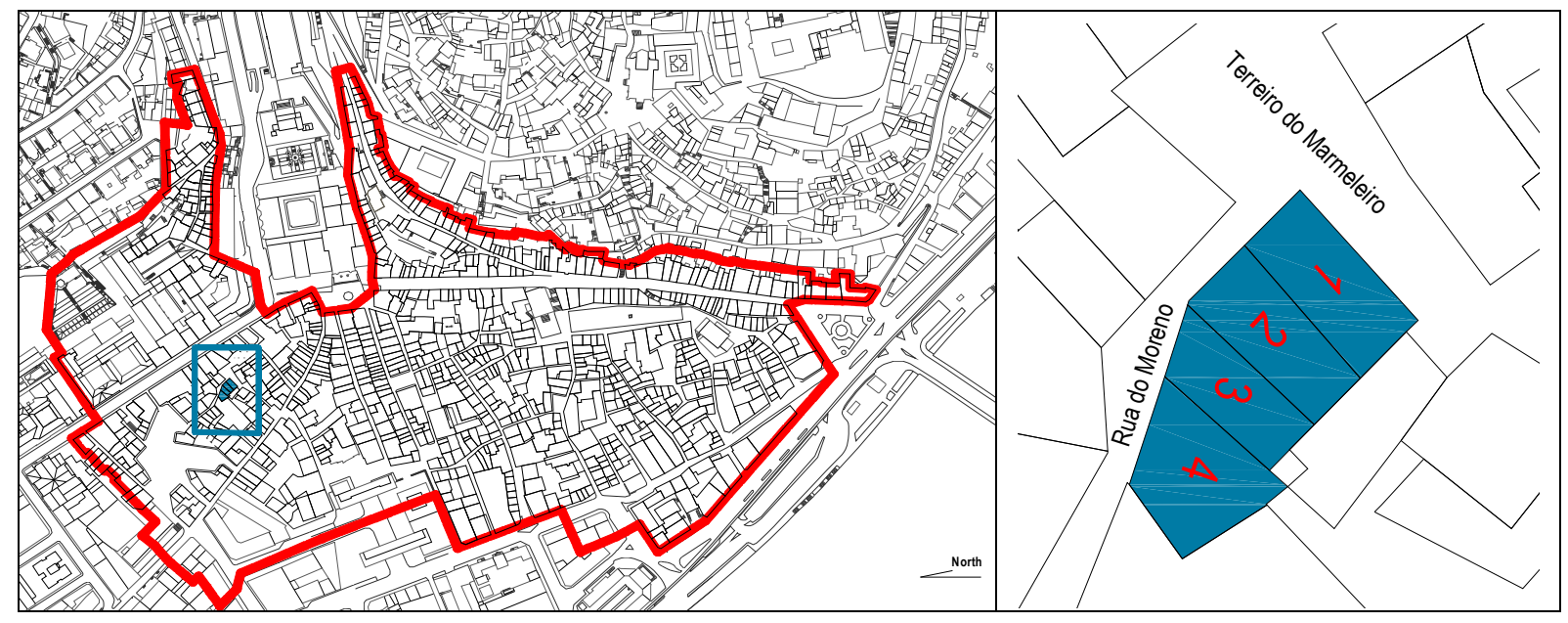

Figure 1: Perimeter of the old city centre and building aggregate studied.

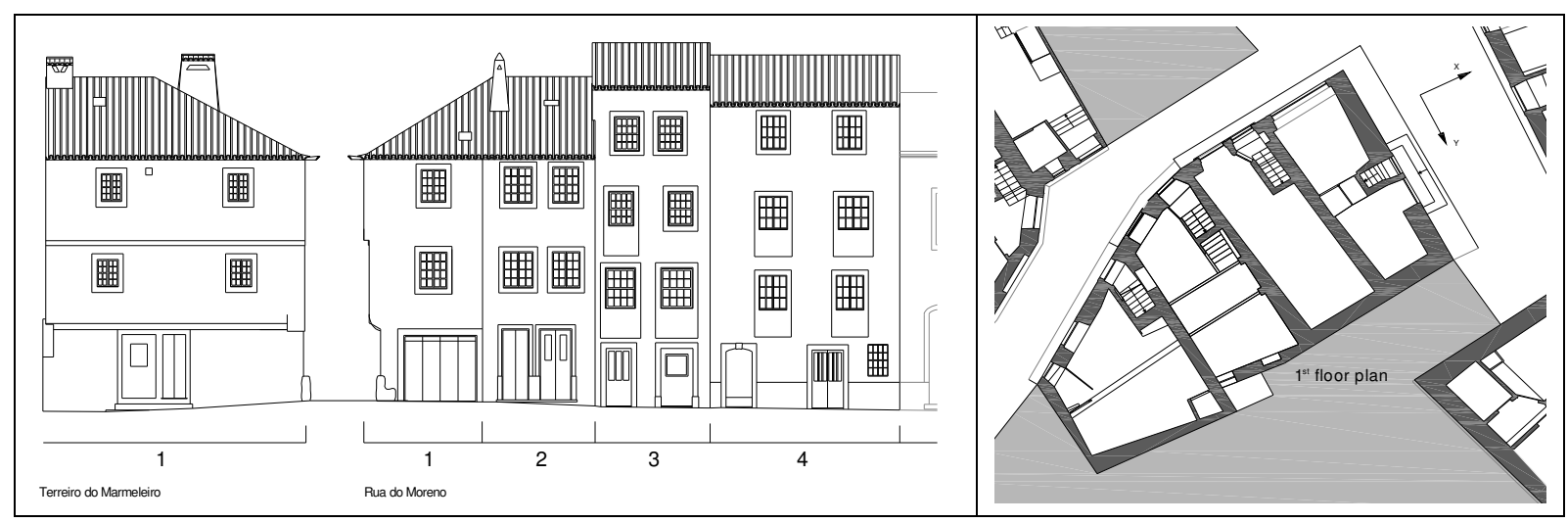

Figure 2: Building drawings and layout.

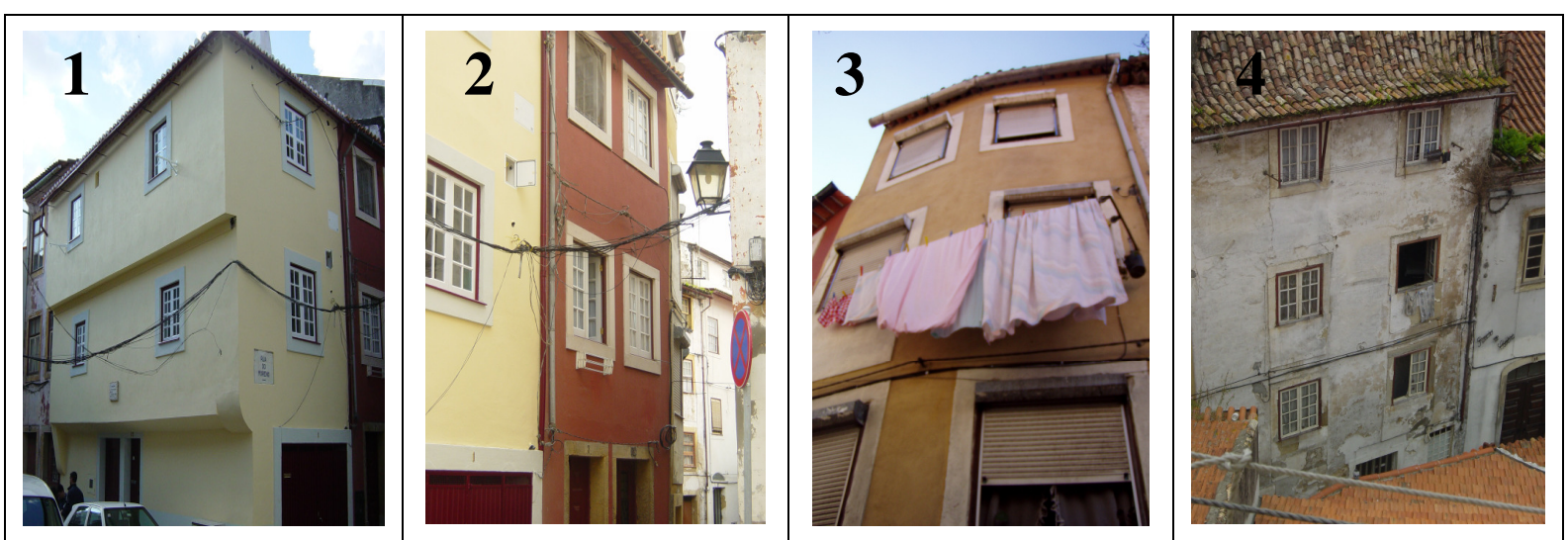

Figure 3: Building façades of the four buildings studied.

An important aspect is the evolution of the urban layout because of the chronological construction process in which adjacent buildings share load-bearing masonry walls and others use existing masonry and partition walls for floor and roof support and connections. The buildings do not constitute independent units given that they share the mid-walls with adjacent buildings. This way, the buildings do not have an independent structural behaviour, but they interact amongst themselves, mainly for horizontal actions and so the structural 
performance should be studied at the level of the aggregate and not for each isolated building.

This reality is important not only for the vertical load-bearing capacity but also for seismic actions, and hence seismic vulnerability. Most of the row buildings lack of good connections between walls and particularly at wall angles. Cracking and collapse of the front and back façades during earthquakes is the most frequent failure system caused by this fragility.

Based on the analysis of the geotechnical reports, the four buildings are founded on plan and horizontal silty clay and sand soil layers with some gravel and filling material. Each of those buildings has approximately a rectangular plan, with exception of building 4 located in the N-W corner of the group, which possesses a trapezoidal form.

Regarding the geometry in height, buildings 1 and 2 (in the S-E quadrant) are constituted by ground floor, two elevated floors and an attic. Buildings 3 and 4 are composed by ground floor, three elevated floors and an attic. Typically, these buildings have no basement, since the major area of this part of the historical centre of the town is quite close to the river.

Architectural typology and traditional construction techniques are variable in role of the dimension and nobleness of buildings. In respect to housing buildings, very simple structural schemes are observed: load-bearing external stone masonry walls and wooden floor slabs (see figure 4).

In the majority of buildings that were inspected and in particular these four buildings, it was observed the systematic use of wood, in structural elements of floors, roofing structures, floor coverings and interior partition walls. Mainly, it was registered the abundant use of dolomitic limestone in external load-bearing walls and the wall thickness varies, normally, in height from a mean value of $50 \mathrm{~cm}$ (at ground level) to $26 \mathrm{~cm}$ at roof level. The use of river sand for bed joints and external mortar renderings is also very common. In most cases roofs are covered with clay tiling. Window sashes are predominantly in wood with simple glazing windows. Interior partition walls are thin and sometimes suffer warping, revealing some kind of structural deformation, often as consequence of creep and aging phenomena.

The masonry walls constitute the main structural elements with the wooden floor slabs resulting in a very simple box-type structure. The masonry fabric is constituted by stones of small to medium dimension, linked with lime and clay mortar. Some of the thinner masonry (near openings and staircase structure) incorporate timbered crossed elements. These stone masonry walls expect to have globally a good behaviour in compression, usually induced by gravity forces, and not for flexural, shear or tensile actions. The weak shear and tensile strength depends on the geometric characteristics of the masonry and its components, to their connection, and to the materials characteristics (stone size, masonry arrangement and stone laying, type of transversal connection between wall faces, type of natural stone, type of mortar).

The floors are considered as flexible diaphragms with small beams and joists with sections of $0.10 \times 0.20 \mathrm{~m}^{2}$ disposed perpendicular to the mid-walls (parallel to the façades). The wood frequently used is national pitch-pine wood and, in some cases, oak and chestnut. The timber floors contribute to increase the global stiffness of the buildings, mainly in the direction of the timber framework, contributing to the resistance to the horizontal actions in that direction. Hence, the floor diaphragms possess a weak axial rigidity to distortion.

The roofs are typically sloped in two directions, the timber roofing structure in constituted by timber elements of $0.10 \times 0.16 \mathrm{~m}^{2}$ for rafters and beams and $0.12 \times 0.20 \mathrm{~m}^{2}$ for the roof ridge beam. These roofs exert an outward thrust on the supporting walls and other are framed as to give a vertical resultant reaction. Only one of the buildings has a timber framed truss. 


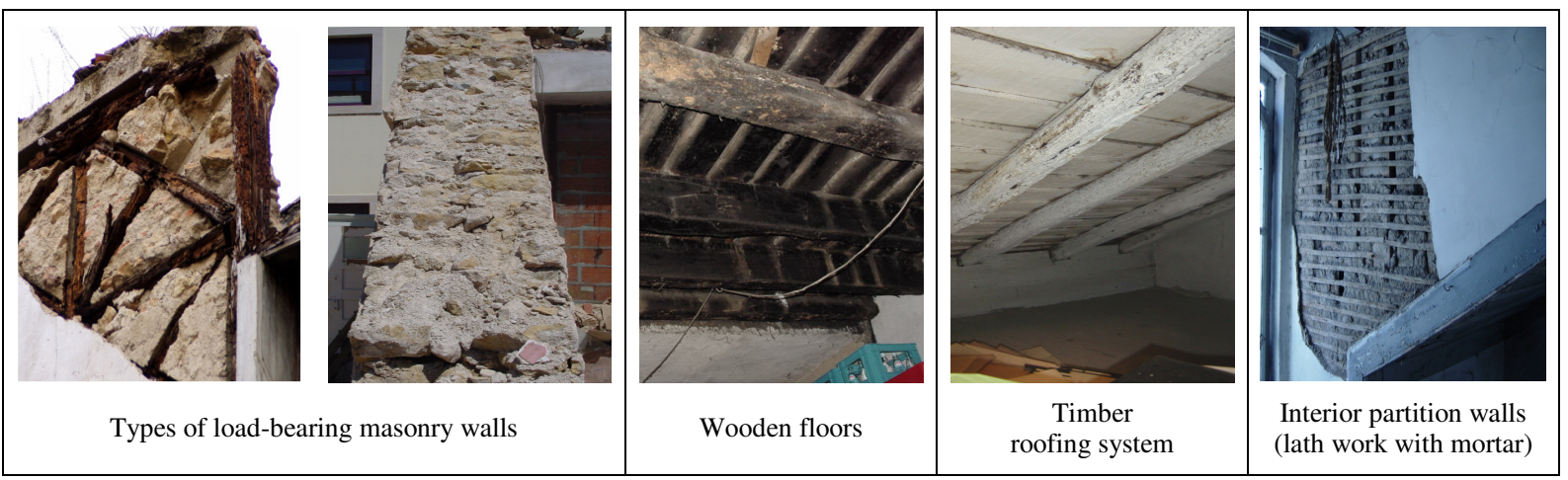

Figure 4: Construction details of old housing.

\section{NUMERICAL MODELLING}

To understand the dynamic behaviour of the old constructions, an aggregate of four buildings was modelled with a finite element tool. The results of these models will aid in the identification of fragile areas [3] of the buildings and in the vulnerability evaluation of the aggregate. With this numerical analysis it is intended: i) to estimate the natural frequencies and vibration modes for the original structure and for different strengthening solutions; and, ii) to understand the seismic behaviour of the structure through global results in terms of displacements, drifts and stresses, for different levels of seismic input actions.

\subsection{Definition of the finite element global model and material properties}

The structural model to simulate the behaviour of the group of buildings was developed using the finite element program Robot Millenium v17.5 [4]. The structural geometry of the buildings was defined starting from drawings in digital format (CAD) and complemented with technical visits. The global three-dimensional structural model mesh was defined with fournodes shell elements for the masonry, and two-nodes bar elements for timber beams, joists and rafters, as shown in figure 5.

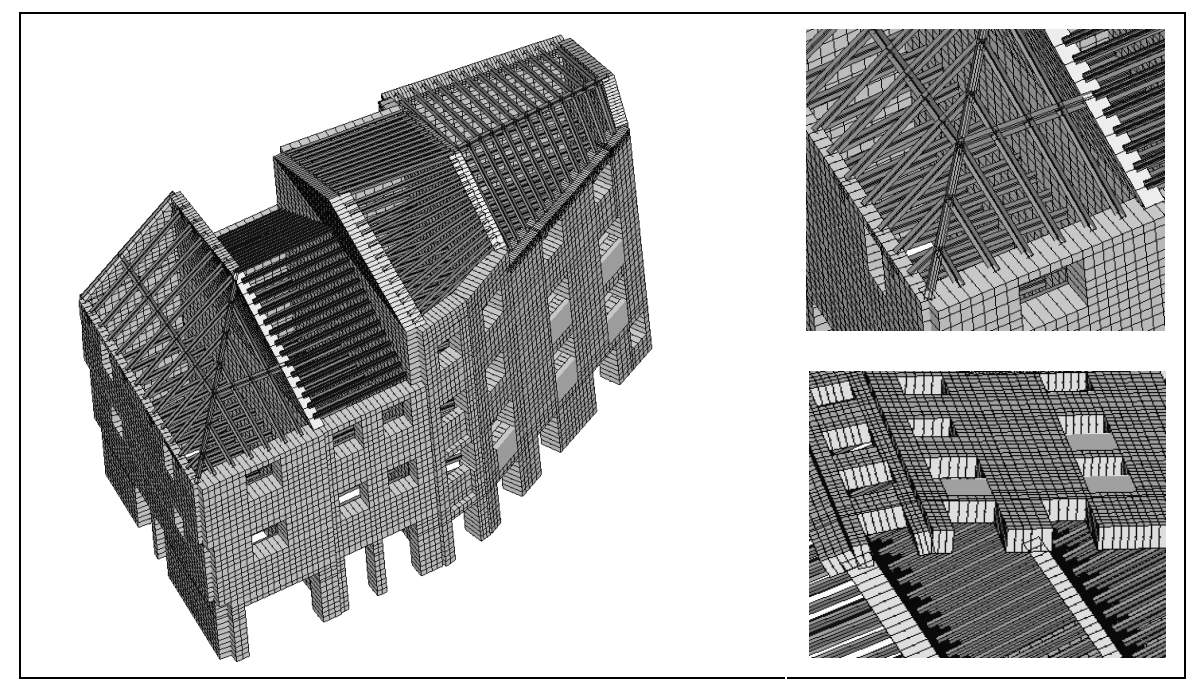

Figure 5: Three-dimensional model. 
The linear elastic models can supply important results for the first global evaluation of traditional structures, particularly in what concerns the identification of critical regions and also helps in the analysis of potential causes of observed structural damages.

A finite element model should be capable of well representing the global behaviour of the construction and particular regions with distinctive behaviour (material connection and compatibility, linkage quality, material). Therefore, some basic assumptions must be put forward:

- Two types of masonry materials were used, namely one for common masonry walls and other for the thinner stone panels (under window panes);

- The floor joists were modelled with hinges at the connection to the masonry walls but with continuity restraining the out-of-plane movement of the masonry walls connected to them;

- The roof structure was considered in the model by bars elements;

- Linear elastic behaviour for all materials considered;

- Rigid support conditions in all points at the base of the walls, restraining the displacements in the three directions of these points, as shown in figure 6 . This assumption was made based on a condition of fair quality of the foundations;

- Assumed behaviour factor equal to 1, corresponding to a situation of unavailable ductility and energy dissipation capacity;

- The roof structure system of the building number 2 (see figure 2) was rehabilitated in the last decade and is constituted by precast concrete beams.
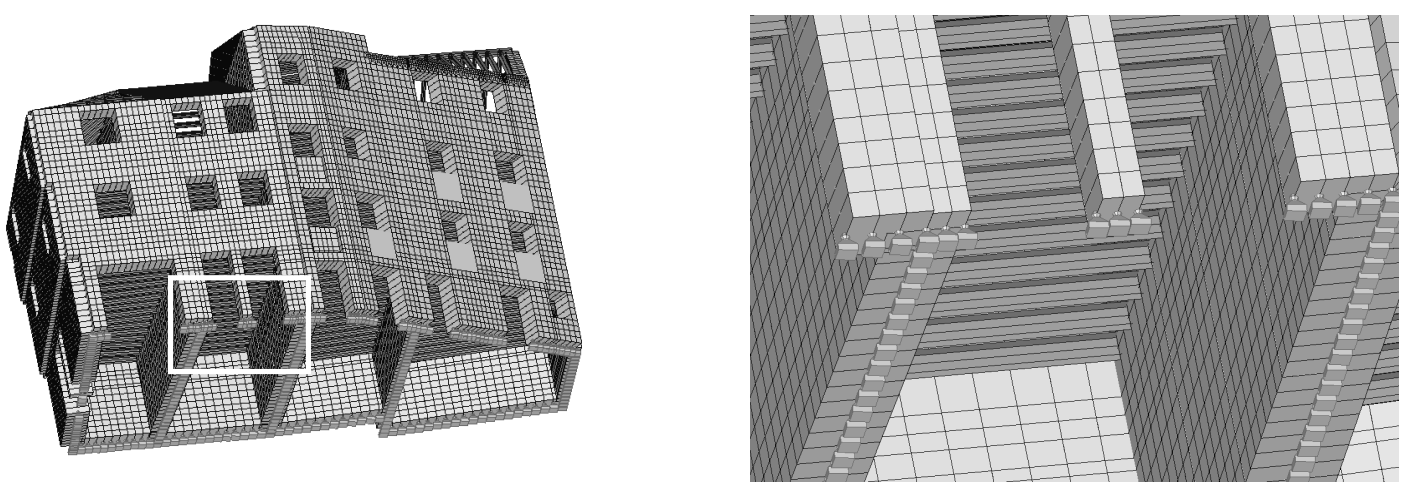

Figure 6: Support conditions.

\begin{tabular}{lcccc}
\hline Material properties & Masonry & Stone panels & Timber elements & Concrete beams \\
\hline Modulus of elasticity, $\mathrm{E}(\mathrm{MPa})$ & $\mathrm{E}=320$ & $\mathrm{E}=3000$ & $\mathrm{E}=6000$ & $\mathrm{E}=35000$ \\
Density, $\gamma\left(\mathrm{kN} / \mathrm{m}^{3}\right)$ & $\gamma=19.6$ & $\gamma=20.0$ & $\gamma=6.0$ & $\gamma=25.0$ \\
Poisson ratio, $v$ & $v=0.2$ & $v=0.2$ & $v=0.2$ & $v=0.2$ \\
Compression strength, $\sigma_{\mathrm{c}}(\mathrm{MPa})$ & $\sigma_{\mathrm{c}}=1.0$ & $\sigma_{\mathrm{c}}=3.0$ & $\sigma_{\mathrm{c}}=11$ & $\sigma_{\mathrm{c}}=17.0$ \\
Tensile strength, $\sigma_{\mathrm{t}}(\mathrm{MPa})$ & $\sigma_{\mathrm{t}}=0.05$ & $\sigma_{\mathrm{t}}=0.05$ & $\sigma_{\mathrm{t}}=18.0$ & $\sigma_{\mathrm{t}}=2.5$ \\
Shear strength, $\tau_{\mathrm{u}}(\mathrm{MPa})$ & $\begin{array}{c}\text { (theoretically zero) } \\
\tau_{\mathrm{u}}=0.04\end{array}$ & $\begin{array}{c}\text { (theoretically zero) } \\
\tau_{\mathrm{u}}=0.05\end{array}$ & $\tau_{\mathrm{u}}=2.0$ & -- \\
\hline
\end{tabular}

Table 1: Properties of the structural materials considered in the numerical model. 
Regarding the structural elements, representative values collected from bibliography were used for timber and stone masonry mechanical properties $[5,6,7]$. In table 1 are shown the material properties considered in the analysis.

\subsection{Dynamic analysis and static loads}

In order to evaluate the seismic performance of the building aggregate, a spectral analysis was performed modelling the seismic action by means of a acceleration response spectrum, acting along the two independent horizontal directions. The acceleration spectrum used is based the Portuguese Standard [8] (seismic action type II (far-distance earthquake), soil type II - coherent soil, 2\% damping and seismic zone C), presented in figure 7.

According to the Portuguese Code, the modal analysis is performed using the serviceability limit state combination $\left(1.00 \cdot \mathrm{G}_{\mathrm{k}}+1.00 \cdot \psi_{2} \cdot \mathrm{Q}_{\mathrm{k}}\right)$. The permanent loads $\left(\mathrm{G}_{\mathrm{k}}\right)$ contemplate the self-weight (masonry walls, timber members, coverings and interior partition walls). The live load $\left(\mathrm{Q}_{\mathrm{k}}\right)$ considered is $2.0 \mathrm{kN} / \mathrm{m}^{2}$ and for roofing structures $1.0 \mathrm{kN} / \mathrm{m}^{2}$.

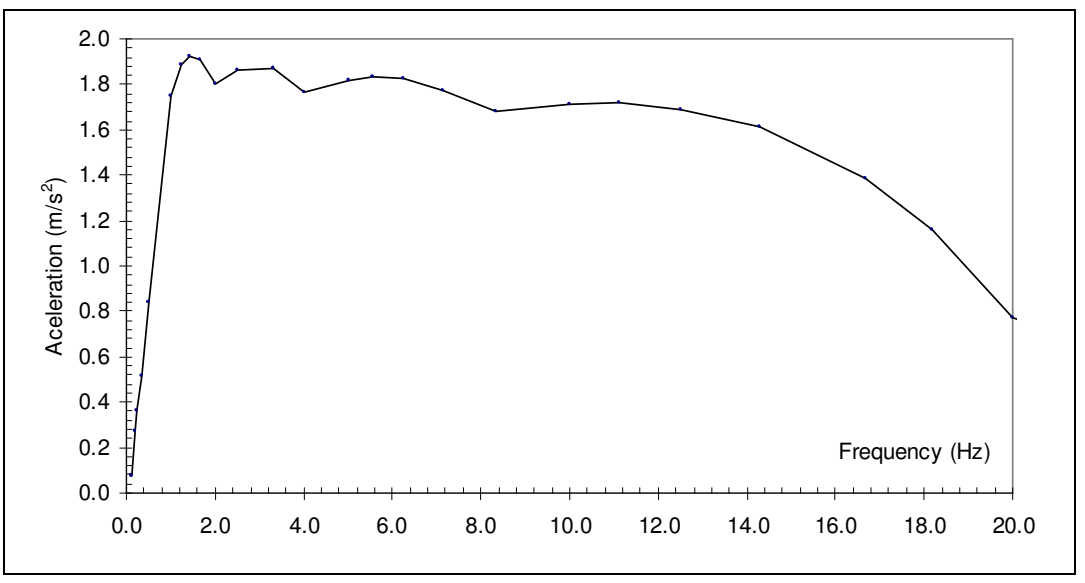

Figure 7: Response spectrum (Portuguese standard, RSA).

\subsection{Strengthening techniques}

Rehabilitation and structural strengthening schemes to enhance seismic resistance for masonry buildings should improve the global structural behaviour and respect the original building materials and techniques [9].

This numerical study was also oriented in the sense of evaluating possible strengthening solutions. Three strengthening solutions adequate for this type of construction, to reduce seismic vulnerability, were analysed: floor stiffening, tie-rods and masonry consolidation.

Introducing tie-rods at floor level and roof ridge level to retain and prevent the out-of-plane mechanisms of the façade, gable and mid-walls and transfer the inertial forces using $25 \mathrm{~mm}$ diameter steel tie-rods is the less intrusive rehabilitation scheme proposed (see figure $8-$ solution B). The steel tie-rods were modelled as truss elements only with tensile strength (non-linear material behaviour), with the characteristics indicated in table 2.

A possible action to improve the global behaviour of the structure could be through the floor stiffening. The in-plane stiffening of the floor diaphragms was modelled by introducing diagonal and orthogonal timber bars with similar characteristics to the original wooden slab framework, as shown in figure 8. (solution A)

Taking into account that the typical stone masonry of these buildings have poor shear and flexural strength, the wall strengthening measures such as improving bond conditions using 
transversal wall connectors, mortar joint pointing, void filling and confining stainless steel mesh embedded in a plaster mortar layer (see figure 8 - solution $\mathrm{C}$ ). This measure was modelled by increasing the elasticity modulus of masonry in $75 \%$, value adopted from experimental studies developed by Costa [10].

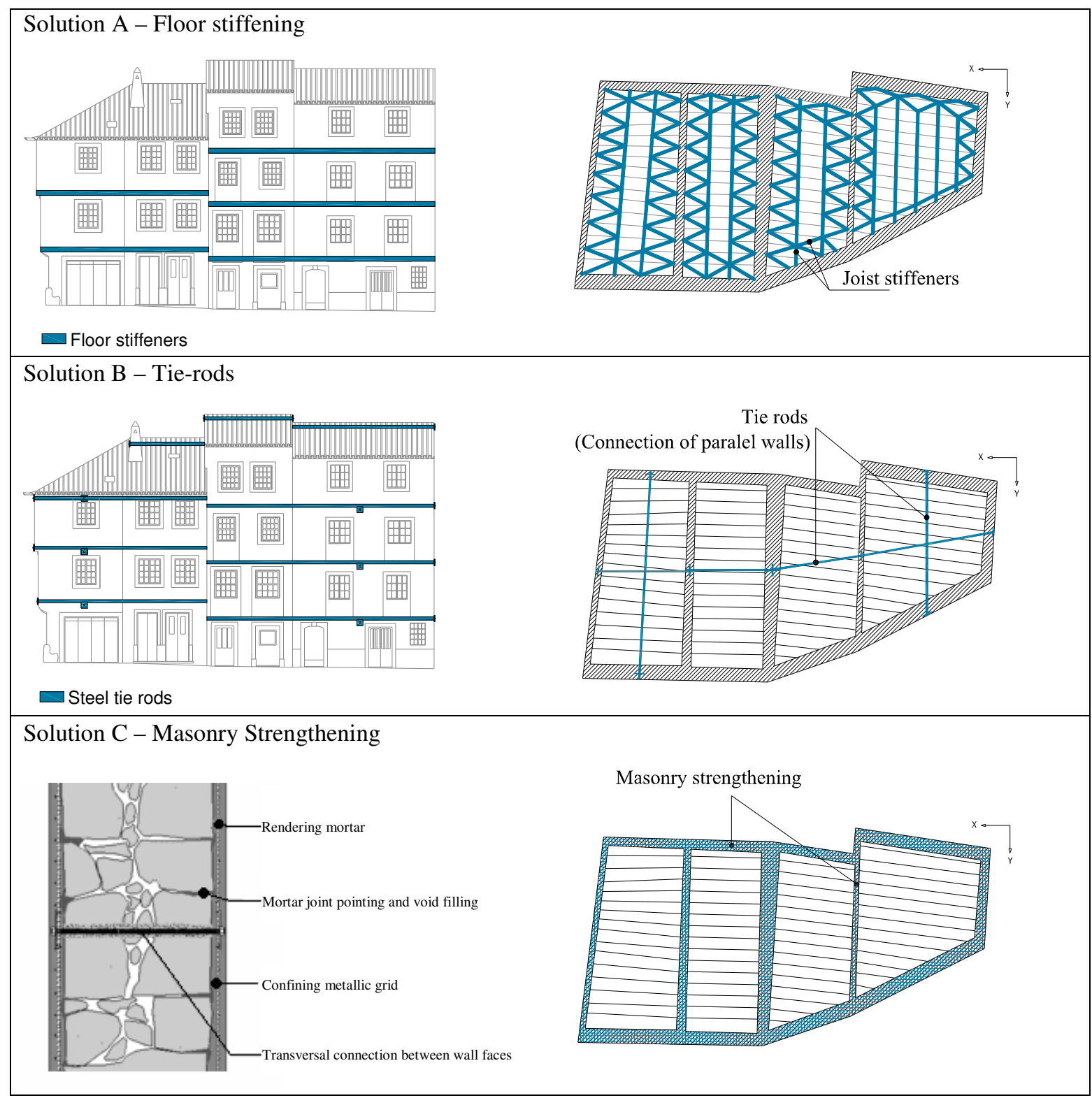

Figure 8: Rehabilitation schemes.

\begin{tabular}{lcc}
\hline Material properties & Strengthened stone masonry & Steel tie-rods \\
\hline Modulus of elasticity, E $(\mathrm{MPa})$ & $\mathrm{E}=560$ & $\mathrm{E}=210000$ \\
Density, $\gamma\left(\mathrm{kN} / \mathrm{m}^{3}\right)$ & $\gamma=19.6$ & $\gamma=20.0$ \\
Poisson ratio, $v$ & $v=0.2$ & $v=0.2$ \\
\hline
\end{tabular}

Table 2: Properties of the materials considered in the strengthening schemes studied. 
Even though the connection quality between walls is not evaluated in study, it is underlined the crucial importance of an efficient connection between main structural elements (wall-floor, roof-wall, wall-wall) in the global structural response.

\section{RESULT ANALYSIS}

\subsection{Modal analysis}

For any structural strengthening intervention, it is important to estimate the dynamic characteristics of the structure (natural frequencies and vibration modes). Therefore, the vibration modes were determined performed for the six different models studied: i) Original structure; ii) Original structure without timber roofing system; iii) Original structure without timber roofing system and floor diaphragms; iv) Retrofitting solution A (floor stiffening); v) Retrofitting solution B (tie-rods); and vi) Retrofitting solution C (masonry strengthened), whose results for the frequencies of the first five vibration modes are summarized in table 3.

\begin{tabular}{lccccc} 
& \multicolumn{5}{c}{ Frequency $(\mathrm{Hz})$} \\
\cline { 2 - 6 } & $1^{\text {st }}$ Freq & $2^{\text {nd }}$ Freq & $3^{\text {rd }}$ Freq & $4^{\text {th }}$ Freq & $5^{\text {th }}$ Freq \\
\hline $\begin{array}{l}\text { Original structure } \\
\text { (with timber roof and floor diaphragms) }\end{array}$ & 1.488 & 2.099 & 2.512 & 2.723 & 2.963 \\
\hline $\begin{array}{l}\text { Masonry walls only } \\
\text { (without timber roof and without floor diaphragms) }\end{array}$ & 1.241 & 1.329 & 1.549 & 1.646 & 1.982 \\
\hline $\begin{array}{l}\text { Masonry walls and floor slabs } \\
\text { (without timber roofing system) }\end{array}$ & 1.416 & 1.625 & 1.997 & 2.198 & 2.29 \\
\hline $\begin{array}{l}\text { Solution A } \\
\text { floor stiffening) }\end{array}$ & 1.813 & 2.273 & 2.800 & 3.218 & 3.451 \\
\hline $\begin{array}{l}\text { Solution B } \\
\text { (tie-rods) }\end{array}$ & 1.632 & 2.188 & 2.640 & 2.999 & 3.081 \\
\hline $\begin{array}{l}\text { Solution C } \\
\text { (masonry strengthening) }\end{array}$ & 1.902 & 2.725 & 3.242 & 3.443 & 3.859 \\
\hline
\end{tabular}

Table 3: Natural frequencies.

About $70 \%$ of the total mass is due to the masonry walls. Therefore, the total mass of the structure does not change significantly with the strengthening schemes (tie-rods or floor stiffeners). From the analysis of the natural frequencies estimated, the following can be concluded:

i) The roofing and timber floor increase the first frequency in $20 \%$, when compared to the masonry wall model. However, the roofing system influence is about 5\% (note that the roofing system for the buildings is not considered framed, therefore outward thrust is possible.

ii) The inclusion of tie-rods increases the first frequency about $10 \%$, but is an effective strengthening measure in terms deformation reduction;

iii) The floor stiffening strengthening scheme increases the frequency in about $22 \%$. The frequencies for the consolidation of the masonry increase of about $30 \%$.

In figure 9 are presented the first three modes of the original structure and each strengthening solution studied: 
Vicente R., Rodrigues H. and Varum H.

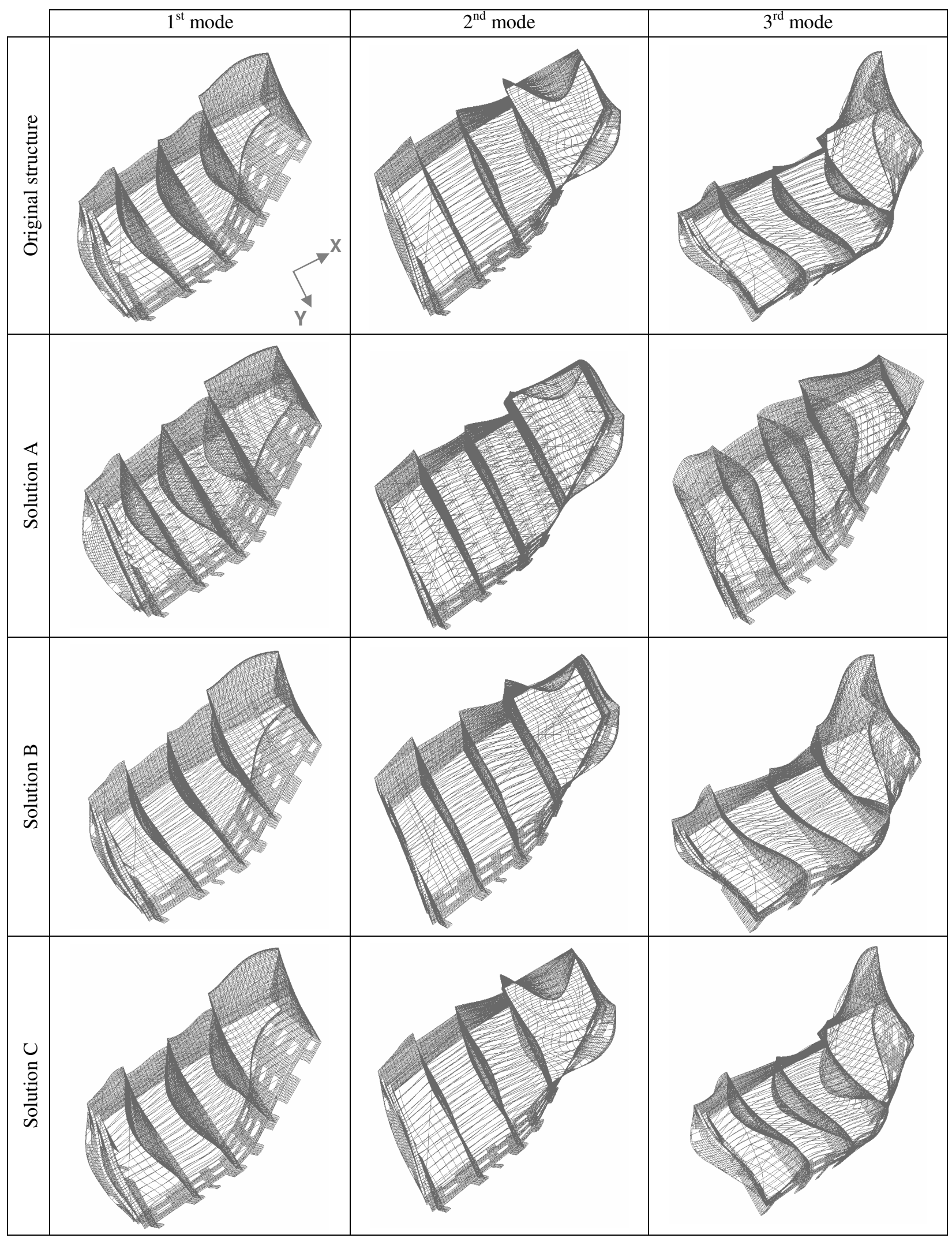

Figure 9: First three vibration modes. 
From the analysis of the mode shapes, presented in figure 9, the following can be advanced:

- The first mode, for all the structural systems analysed, shows essentially the translation along the longitudinal direction (X). For the first modes, the ground floor presents a significant deformation, due to the high number of openings in direction $\mathrm{X}$. The first mode shapes evidences the high vulnerability of some masonry walls to the out-of-plane movement (façade wall of buildings 1 and 4, and internal mid-walls);

- With the retrofitting solution A, the increased in-plane stiffness of the floors reduces the out-of-plane movement of the walls. The absence of floor diaphragm at the attic level aggravates the top-displacement of the mid-walls and of the façade walls in the longitudinal direction, $\mathrm{X}$;

- With the retrofitting solution B (tie-rods), for the first natural mode, the out-of-plane movement of the masonry walls is smaller than in the original structure, and for the other two strengthening solutions;

- The masonry strengthening solution (C) produces a similar first mode shape if compared with the original structure;

- For building 4, the façade and gable-end wall suffers mostly from a torsional movement since it has a diagonal direction in relation to the principal directions, $\mathrm{X}$ and Y;

- For the 3rd mode, the floor in-plane stiffening (solution A) prevents the torsional movement verified in the other structural models. However, for mode shapes superior to the $3 \mathrm{rd}$, the global torsional movement and in-plane floor deformation associated to out-of-plane movements of façades is verified. For some superior mode shapes, the out-of-plane movements of the walls in both directions are considerable.

\subsection{Displacement and drift profiles}

From the observation of masonry damages, in recent earthquakes, it is evident the concentration at regions with highest demand, such as corner angles and façades. In this section are presented the displacement profile, numerically evaluated, at crucial points of the structure, namely: corner angles, front façade and internal mid-walls. In the next, are presented the most relevant results obtained with the spectral analysis for the design earthquake level for Coimbra, since 16 points were controlled in both directions (X e Y).

In figure 10 can be observed the displacement amplitude profile at point 3, for each direction analysed of the structures.

The tie-rod solution does not have a significant effect on the deformation control of the corner angle, but does certainly help in mobilizing the global response of the structure as a whole. Hence the principal function of the tie-rod referring to its axial stiffness, in comparison with the flexural stiffness of the masonry wall, is to control the out-of-plane deformation of the façades.

The floor diaphragms stiffening presents to be a good strengthening technique essentially in the $\mathrm{X}$ direction, reducing the top-displacement of about $18 \%$ in this direction and $8 \%$ in the $\mathrm{Y}$ direction. It must be referred that this solution would have been more efficient if executed also for the floor diaphragm at attic level, and being the roofing structure framed.

The masonry strengthening is clearly the retrofitting technique that more reduces the topdisplacement (of about 44\%). Also for this strengthening technique analysing the displacement profile in the longitudinal direction, the deformation suffered at the first storey represents around $50 \%$ of the total displacement. 


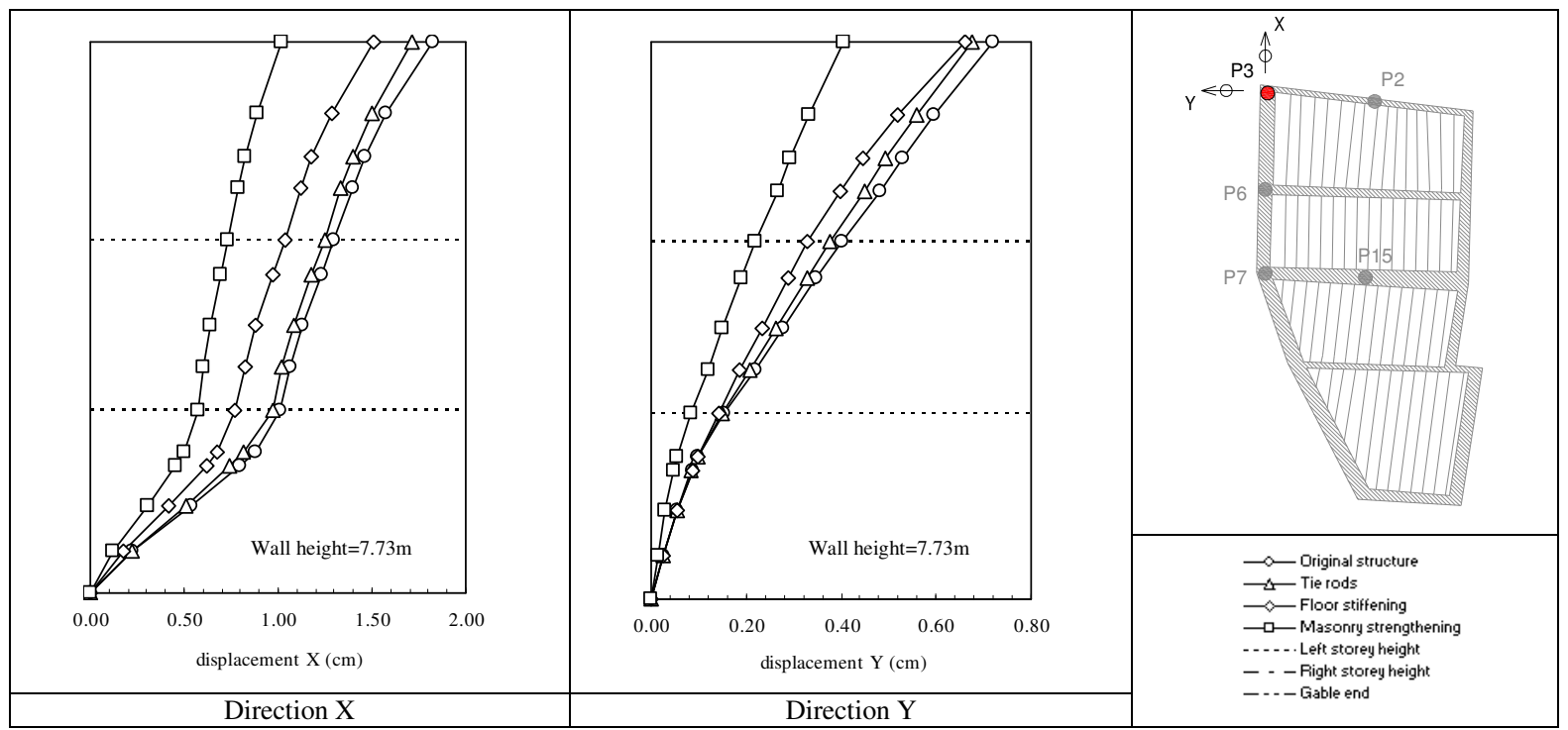

Figure 10: Displacements of the building corner.

Analysing control points P2 and P15 allows evaluating the efficiency of the simulated strengthening solutions in the reduction of the out-of-plane masonry façade wall movement and of the interior mid-walls. From the displacement profile of these points (see figure 11), it is clear that the strengthening solution which more reduces the top-displacement is the masonry wall strengthening (reduction of about $40 \%$ ).

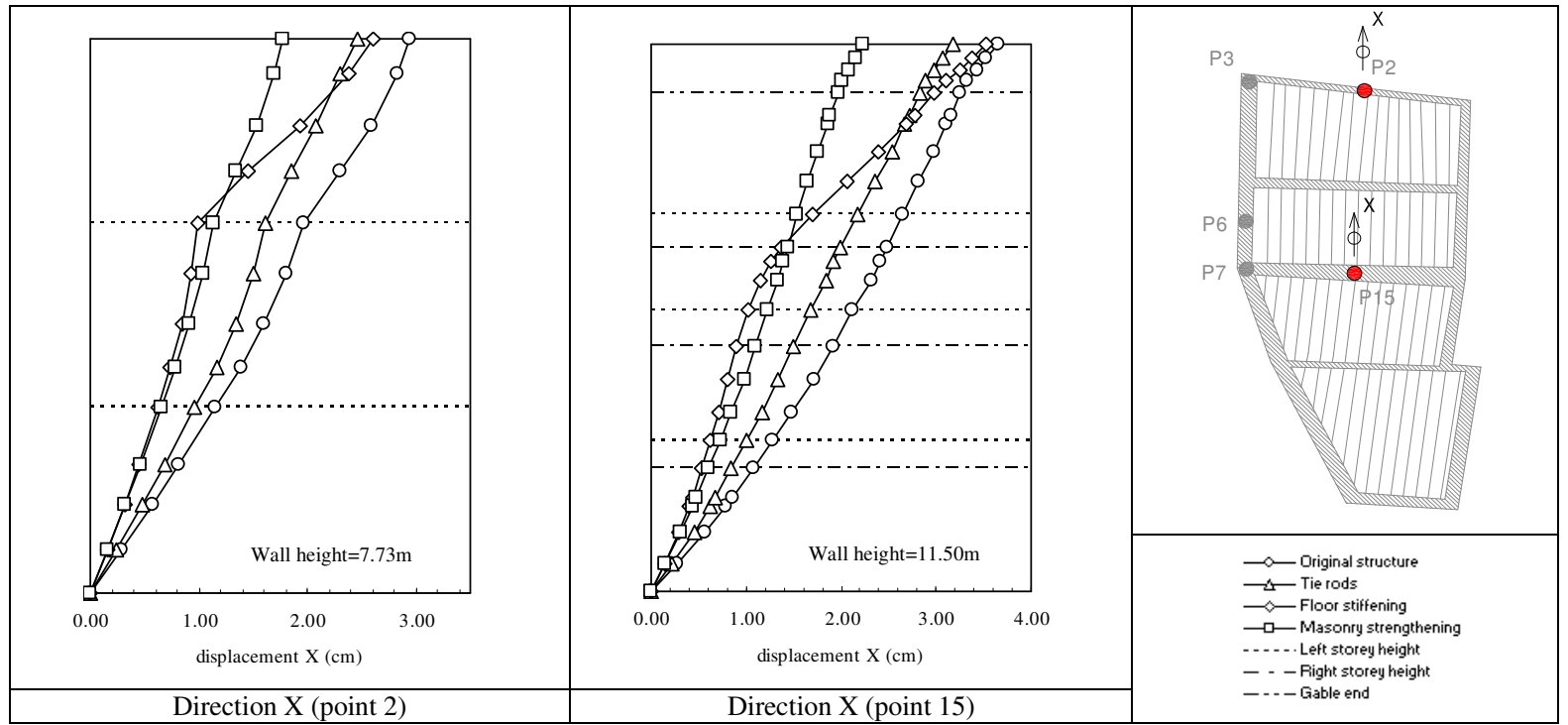

Figure 11: Out -of-plane displacements of the façade.

The analysis of the floor stiffening (solution A) retrofitting technique, demonstrates the efficiency of the diaphragm stiffening in the deformations reduction, in comparison to all other retrofitting solutions till the height of the last stiffened diaphragm. For superior levels, the horizontal displacement is amplified, and originates higher inter-storey drifts. This out-ofplane movement is also amplified with the existent and simulated heavier concrete roofing system of building 2 . 
The tie-rod solution allows a reduction of the top-displacement, principally caused by the tie-rod at roof level. But, associated to this reduction, surges a displacement at lower floor levels of 40 to $60 \%$ higher than the verified for the other strengthening solutions.

The analysis of point 6 (wall façade) reveals that the displacement of the wall in the inplane direction $(\mathrm{X})$ is higher than for the out-of-plane direction $(\mathrm{Y})$, see figure 12.

Once again, in both directions, the masonry strengthening is the most efficient method reducing about $45 \%$ of the top-displacement. In the Y-direction the floor stiffening solution shows discrete improvement of the out-of-plane deformation control (10\%) and, a larger contribution $(22 \%)$ in the X-direction. The floor stiffening solution slightly amplifies the outof-plane deformation.

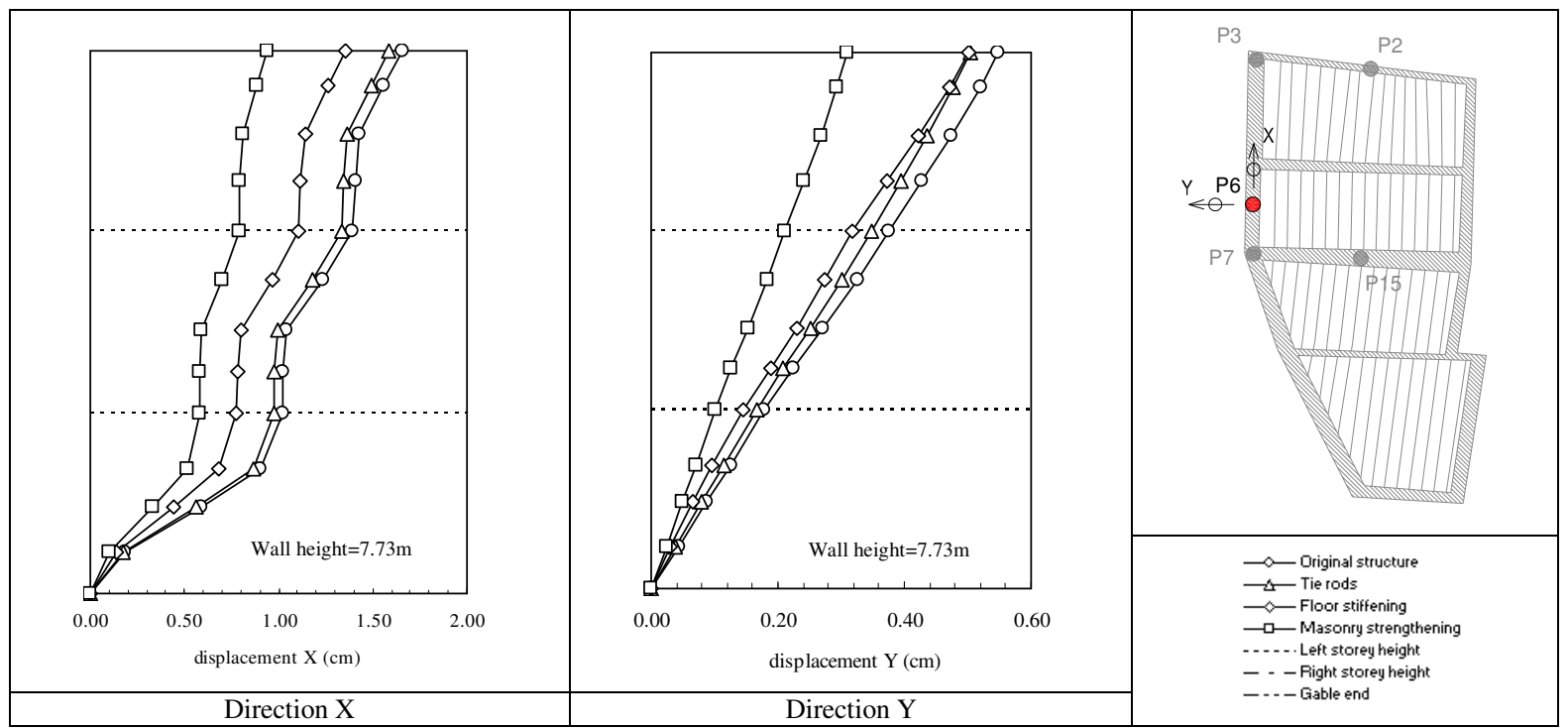

Figure 12: Displacements of point 6.

Results at point 7 indicates a analogous behaviour as point 6 , but in the $\mathrm{X}$-direction the tierod solution and floor stiffening is less influent, representing 5\% and $14 \%$ of deformation control improvement respectively. The masonry strengthening scheme reduces the displacement of about $43 \%$ in both directions (see figure 13).

In figure 14 , analysing the inter-storey drift profile for point 2 , it can be seen the negative phenomenon introduced by the absence of floor stiffening the attic floor level. Even though the FEMA-356 document [11] does not indicate out-of-plane inter-storey drift limits for unreinforced masonry walls, it however indicates a geometrical control; height-to-thickness ratio and a damage state control, based on floor accelerations and velocities. In spite of this, the drift for the original structure at the last floor level is of $0.38 \%$ and is aggravated to the value $0.63 \%$ when introduced the floor stiffening measure. On the other hand, the floor stiffening solution reduces significantly floor drifts at the lower levels.

For points 3 and 6 (see figure 14), the high inter-storey drift demands at ground level is due essentially to the high percentage of openings, revealing a soft-storey mechanism. The FEMA-356 in-plane inter-storey drift limits (Immediate Occupancy - 0.1\%; Life Safety $0,6 \%$, Collapse Prevention - $0.8 \%$ ) were also plotted in the graphic of figure 14 . From the analysis of the results, it can be observed that the deformation at all levels and points studied (3 and 6) does not verify the IO performance level, with exception of the upper storeys of the masonry strengthened structure. 


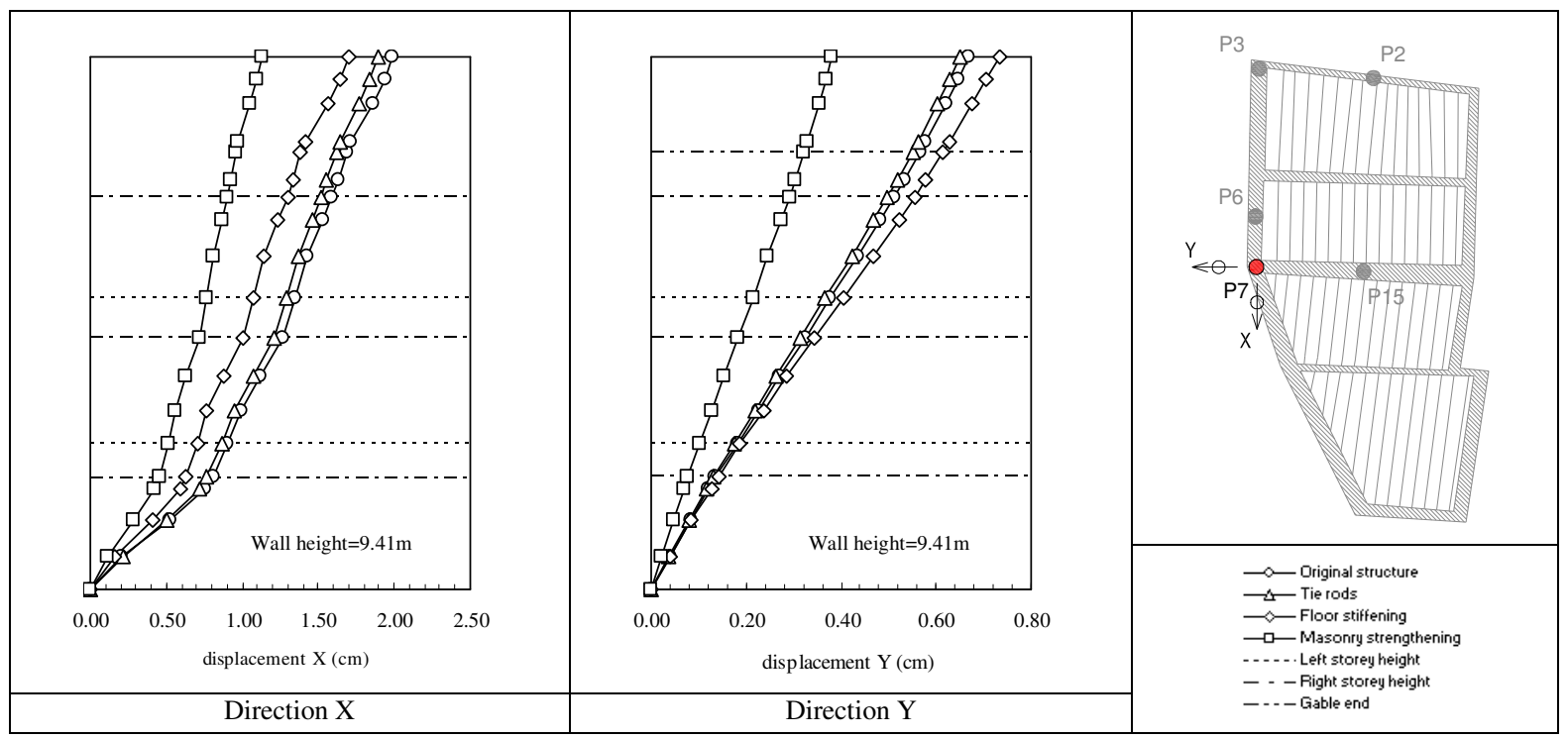

Figure 13: Displacements of point 7.

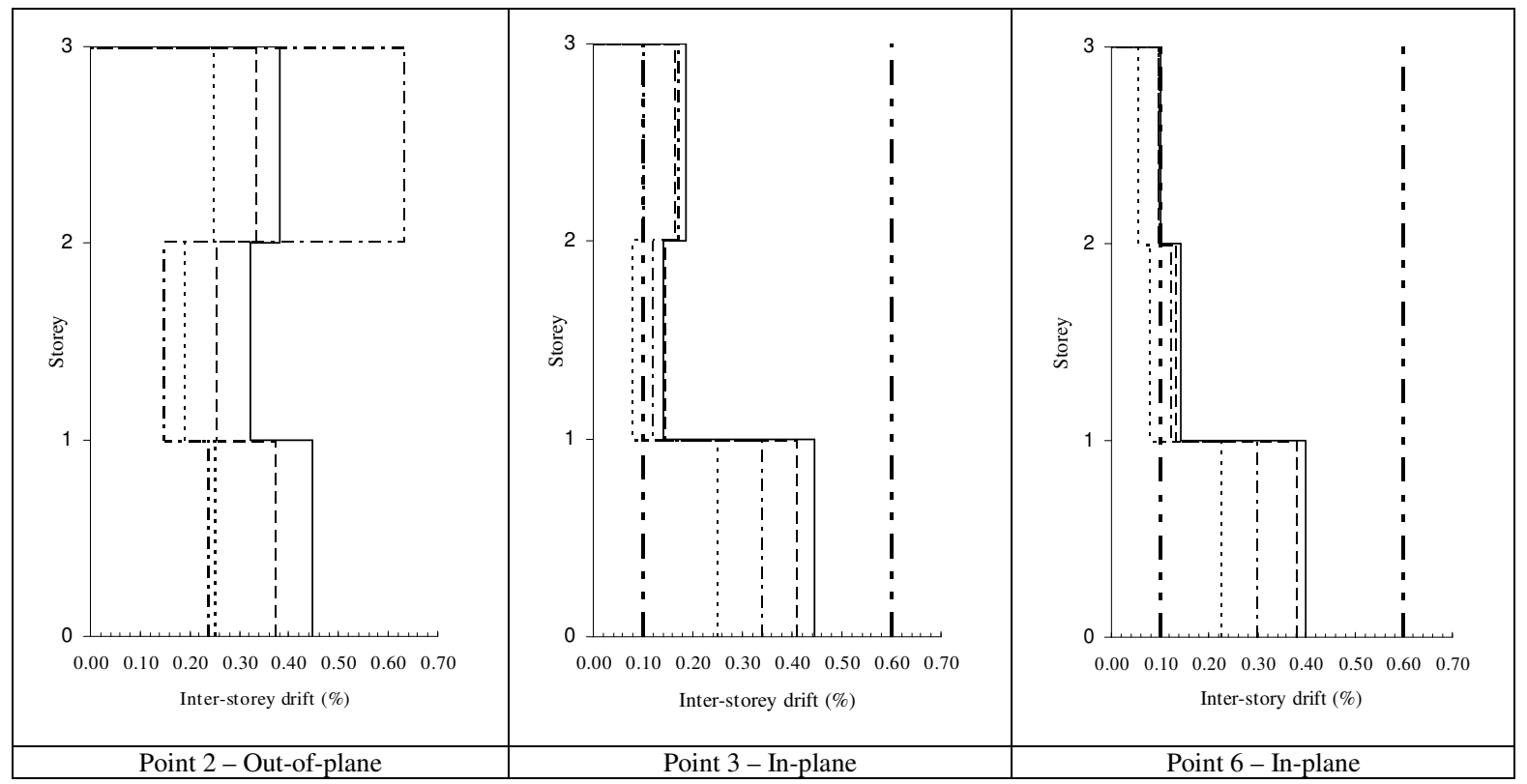

Figure 14: Inter-storey drift profiles for points 2, 3 and 6. 


\subsection{Damage levels - Stress analysis}

The stress concentration at ground floor also demonstrates the demand concentration at this level. (see figure 15). High stress concentration exceeding stone masonry tensile and shear strengths would lead to cracking and, consequently, stiffness reduction would initiate, and a soft-storey mechanism could develop.

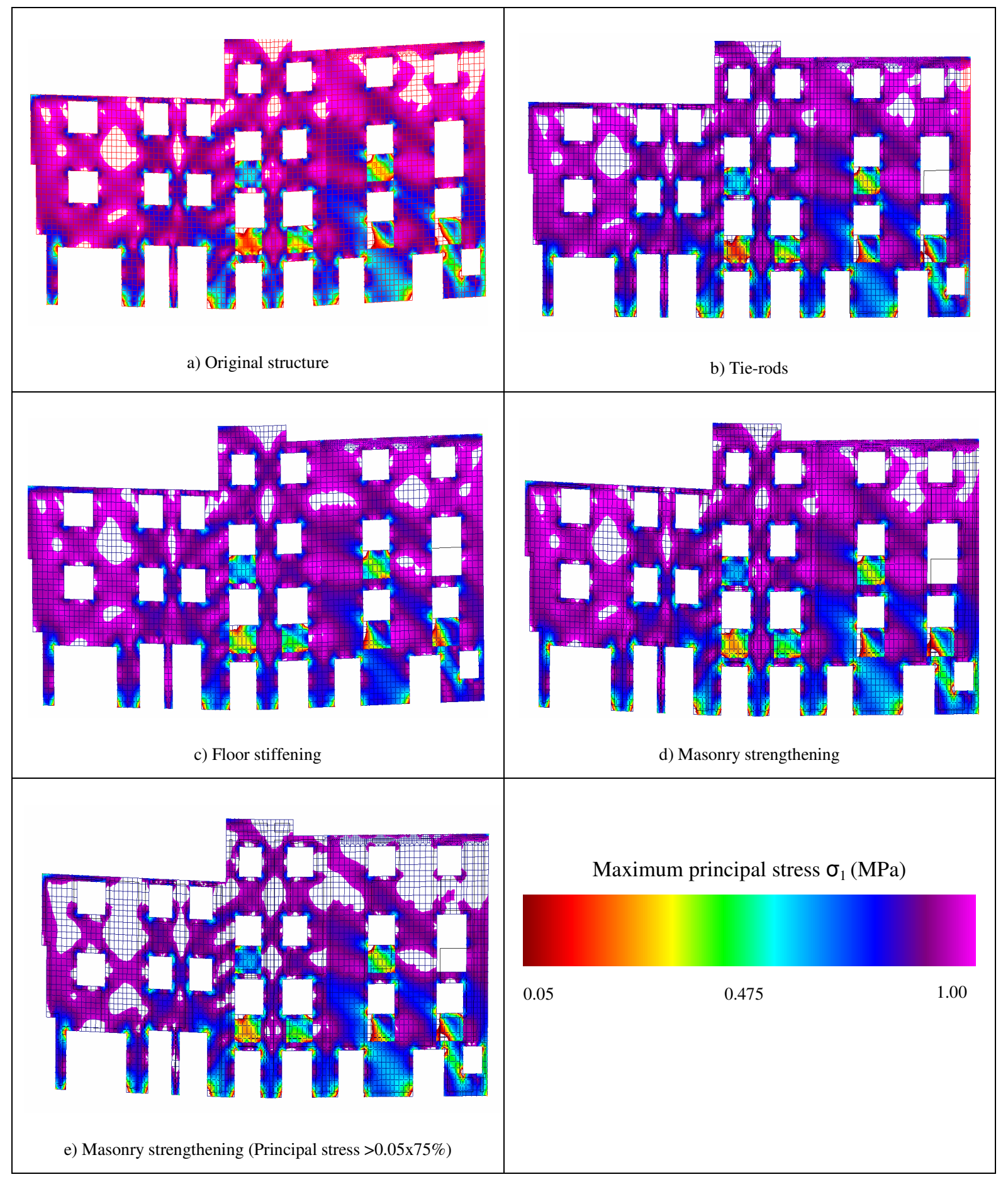

Figure 15: Maximum principal stress distribution. 
The stress concentration in the vicinity of the openings is slightly reduced in strengthen models, particularly for the floor stiffening solution, in which the reduction of the peak stresses is about $30 \%$, and the stresses distribution throughout the front wall façade front is more uniform. Since the stone panels under the window openings are very stiff, when compared to the regular stone masonry, the concentration of tensile stress induces local damage to these elements. It should be noted that the misalignment of façade wall openings in building 4 aggravates the load stress path and potencies the damage concentration.

Assuming that masonry strengthening increases the tensile strength proportionally to the elastic modulus, the damaged area (as seen in figure 15e) is significantly reduced.

\section{FINAL COMMENTS AND CONCLUSIONS}

This study has allowed better understanding the seismic performance of this type of buildings. The numerical analysis performed allows to state:

- The high number and dimensions of openings at ground floor highly influence the wall façades deformation and stress concentration for earthquake acting in the longitudinal direction. Inter-storey drifts are rather high at ground level, which can originate a softstorey mechanism. Openings enlargement or suppress of masonry walls at ground floor, for example, to install commercial spaces or garages is an inadequate practice in old buildings that should not be overlooked;

- The asymmetry of total area of openings between the front and posterior façades induces a global torsion of the group of buildings studied. However, it is recognised that the global behaviour of the overall aggregate, where the buildings are included, attenuates the torsional effects mentioned;

- The masonry walls are very vulnerable to the out-of-plane deformations. The connection to the floor timbered structures and with orthogonal walls are important measures to reduce its vulnerability to the out-of-plane collapse mechanisms, which are particularly important for higher floor levels, as observed in the displacement profiles;

- From the retrofitting techniques studied, masonry strengthening has revealed to be the most efficient technique in reducing the displacements (out-of-plane and in-plane);

- Increasing the diaphragm stiffness can be an effective retrofitting solution to improve the global behaviour of old masonry buildings. However, when this strengthening technique is not applied at all floor levels, the deformation demands at the upper storeys could be larger than for the original non-strengthened structure;

- Tie-rods can be efficient in restraining the out-of-plane deformations of masonry walls, As was expected, numerical results indicates that they do not contribute significantly to the in-plane response. Tie-rods are especially effective at roof level, improving the global response;

- The studied strengthening techniques were designed respecting the original conception of the building. Nevertheless, economical cost analysis and intrusion level of these schemes must be considered. Masonry strengthening and floor stiffening are normally costly and intrusive measures, and imply additional costs for the temporary rehousing of residents;

- Combination of the studied strengthening actions could probably be more the most effective strengthening scheme, for example, floor stiffening at all levels, roof tie-rods and masonry strengthening at ground floor level. 
Numerical modelling of historical constructions must be seen as a valuable tool in support to the structural upgrading design and to the definition of suitable and efficient interventions [12]. Experimentation, monitoring and observation are complementary actions that should be developed parallel to the numerical analyses.

\section{ACKNOWLEDGEMENTS}

The authors would like to thank the task group of the Coimbra City Renewal Process for granting the CAD drawings and building information used in this paper.

\section{REFERENCES}

[1] Vicente, R.S.; Silva, J.A.R.; Varum, H., Strategies for building pathology reports in a urban rehabilitation process, 10DBMC International Conference on Durability of Building Materials and Components, Lyon, France, 17-20 April 2005.

[2] Vicente, R.S.; Varum, H.; Silva, J.A.R., Seismic vulnerability assessment of buildings in the old city centre of Coimbra, International Conference $250^{\text {th }}$ Anniversary of the 1755 Lisbon Earthquake, 1-4 November 2005.

[3] Varum, H.; Rodrigues, H., Avaliação do comportamento estrutural da torre medieval de Vilharigues - Vouzela, Congreso de Métodos Numéricos en Ingeniería 2005, Paper $\mathrm{n}^{\mathrm{o}}$ 382, Granada, Spain, 4-7 July 2005 [in Portuguese].

[4] Robot Millennium $v 17.5^{\circledR}$, Three dimensional static and dynamic finite element analysis and design of structures, Robot Office.

[5] Pagaimo, F.A.L., Mechanical characterization of old masonries. Case study of the historical town of Tentúgal, MSc thesis in Civil Engineering, Faculdade de Ciências e Tecnologia da Universidade de Coimbra, 2004 [in Portuguese].

[6] Farinha, J.S.B.; Reis, A.C., “Tabelas Técnicas”, Edições Técnicas E.T.L., 1998 [in Portuguese].

[7] Cardoso. R., Seismic vulnerability of old masonry structures - application to a "Pombalino building, MSc thesis in Structural Engineering, Instituto Superior Técnico, October 2002 [in Portuguese].

[8] RSA, Rules for the definition of actions and safety in buildings and bridges. INCM, 1983 [in Portuguese].

[9] Giuffrè, A., Editore Laterza \& Figli Spa, Sicurezza e Conservazione dei Centri Storici Il caso Ortigia, Rome-Bari, 2000.

[10] Costa, A., Determination of mechanical properties of traditional masonry walls in dwellings of Faial Island, Azores, Earthquake Engineering and Structural Dynamics, 31: 1361-1382, 2002.

[11] FEMA-356, Prestandard and commentary for the seismic rehabilitation of buildings, American Society of Civil Engineers and Federal Emergency Management Agency, Washington D.C, 2000. 
[12] Proceedings of the Structural Analysis of Historical Constructions. Possibilities of numerical and experimental techniques, Padua, Italy, 10-13 November 2004. 